\title{
A Disseminação da Desinformação Promovida por Líderes Estatais na Pandemia da COVID-19
}

\author{
Lucas A. Lisboa ${ }^{1}$, João Victor R. Ferro ${ }^{1}$, José Rubens S. Brito ${ }^{1}$, Roberta Vilhena V. Lopes ${ }^{1}$ \\ ${ }^{1}$ Instituto de Computação - Universidade Federal de Alagoas (UFAL) \\ Maceió - AL - Brasil \\ $\{l a l, j v r f, j r s b, r v v l\}$ aic.ufal.br
}

\begin{abstract}
During the COVID-19 pandemic, there was a rapid spread of misinformation regarding the disease, especially involving state leaders around the world. In this sense, this article analyzes the scope of such uninformative messages, from the use of the Google Trends tool, thus evaluating the level of public demand on the platform in question after the events analyzed. Thus, it was observed that, from the phenomenon of resonance of Koopmans (2004), the general interest of the terms analyzed obtained a significant increase, being represented by high peaks in the searches.
\end{abstract}

Resumo. Durante a pandemia da COVID-19, observou-se a rápida disseminação de desinformação no que tange a doença, especialmente envolvendo líderes estatais a redor do mundo. Nesse sentido, este artigo analisa o alcance de tais mensagens desinformativas, a partir do uso da ferramenta do Google Trends, avaliando, assim, o nível de procura do público na plataforma em questão após os eventos analisados. Dessa forma, foram observados que, a partir do fenômeno de ressonância de Koopmans (2004), o interesse geral dos termos analisados obtiveram um aumento expressivo, sendo representado por altos picos nas buscas.

\section{Introdução}

As notícias falsas, as famosas fake news, já são consideradas um dos maiores problemas da era digital. Tal fato pode ser observado na rápida disseminação delas nos meios virtuais, em especial nas redes sociais, como Facebook e Whatsapp, chegando a ter uma capacidade de propagação $70 \%$ maior que as notícias verdadeiras (VOSOUGHI, ROY e ARAL, 2018). Dessa forma, é possível verificar que as postagens de fake news são muito mais acessadas e compartilhadas em relação às publicações científicas online (BESSI et al., 2015). Tal problemática se tornou tão significativa que o Fórum Econômico Mundial, em 2013, listou fake news como uma das maiores ameaças à civilização moderna (HOWELL, 2013) .

Nessa perspectiva, durante a pandemia da COVID-19, verificou-se a proliferação de inúmeras práticas de desinformação, principalmente as notícias falsas, nos veículos de comunicação em massa, em especial na internet, por meio das redes sociais. Tal disseminação foi promovida, inclusive, por chefes de Estado, os quais, em seus discursos, minimizaram o impacto da doença, divulgaram informações falsas e adotaram posturas que contrariavam a Organização Mundial de Saúde (OMS). 
Assim, este artigo tem a proposta de analisar como se deu a disseminação de desinformação acerca do novo coronavírus ao redor do mundo quando promovida por gestores estatais, adentrando em cada país selecionado para verificar o alcance de tais mensagens, a partir do uso da ferramenta Google Trends.

\section{Metodologia}

A metodologia utilizada neste trabalho consistiu numa seleção prévia de países ao redor do mundo; seguida pela verificação da veracidade das mensagens propagadas e, por fim, a análise da propagação e consequências delas.

\subsection{Definição de Desinformação}

A definição utilizada aqui foi a de Posetti e Bontcheva (2020), a qual foi adotada pela Organização das Nações Unidas para a Educação, a Ciência e a Cultura (UNESCO). Nela, a desinformação é descrita como conteúdos contendo informações falsas ou manipuladas, os quais possuem potencial de causar impactos negativos na sociedade. Nesse sentido, as autoras apontam cerca de nove tipos de desinformação a cerca da COVID-19, sendo elas:

1. Origem e Propagação da Doença: Envolvem teorias conspiratórias acerca da origem do vírus ou utilizam nomenclaturas xenófobas para se referir à doença;

2. Estatísticas falsas ou enganosas: São relacionados à taxa de incidência ou de mortalidade da doença;

3. Impactos Econômicos: Tentam associar que o isolamento social não é economicamente viável;

4. Desacreditar a Imprensa: Tentam descredibilizar os veículos de notícias com acusações duvidosas;

5. Sintomas, Diagnósticos e Tratamento: São pertinentes a algum sintoma, diagnóstico ou tratamento que não possui respaldo científico;

6. Impactos na sociedade e no meio ambiente: São referentes a mensagens de pânico, envolvendo abastecimento de insumos pessoais, ao lockdown de cidades ou a questões ambientais;

7. Partidarização da doença: Associam alguma postura ou problema envolvendo à pandemia a determinado partido ou corrente ideológica;

8. Golpes financeiros: São alusivas ao roubo de dados privados das pessoas;

9. Celebridades com Covid-19: Vinculam histórias falsas sobre celebridades com o diagnóstico da doença.

Durante as análises, foi destacado em que tipo de desinformação a mensagem analisada faz parte.

\subsection{Países Selecionados}

A seleção dos países como objetos de estudo se deu levando em conta dois importantes fatores. O primeiro é a potencialidade de propagação da doença, isto é, foram observados países que, em determinado momento, apresentaram um número alto de casos. O segundo foi que, ao menos, um líder estatal do país selecionado apresentou alguma mensagem com teor desinformativo, seja em discursos, pronunciamentos, entrevistas, posts em redes sociais, ou qualquer outro meio comunicativo oficial. 


\subsection{Google Trends}

Para medir o nível de propagação das mensagens analisadas foi adotada a plataforma do Google Trends, em virtude da alta popularidade do Google como mecanismo de busca pelo mundo.

Os dados do Google Trends são amostras imparciais dos dados de pesquisa do Google, sendo anonimizado, categorizado e agregado (ROGERS, 2016). Assim, é permitido medir o interesse em tópicos específicos a partir da análise em números percentuais, ou seja, é criado um sistema de pontuação, indo de 0 a 100 , em que 0 representa $0 \%$ de interesse e 100 representa $100 \%$ de interesse, o que indica o maior pico de interesse no termo buscado na base de dados do Google.

Os dados dessa pesquisa foram filtrados em tempo não real, sendo adotado o padrão de busca de "Período Personalizado", sendo selecionado o período a partir de 17/07/2019 até 20/04/2020, para comparar a relevância de cada temática antes, durante e após determinado pronunciamento, bem como os padrões "País"(a definir através do termo analisado), "Todas as Categorias"e "Pesquisa na Web".

\subsection{Disseminação}

Nesta etapa, foi utilizada a teoria de Ruud Koopmans (2004), em que foram descritos três importantes conceitos: legitimidade, ressonância e visibilidade. Legitimidade é o quanto determinada mensagem é considerada legitima perante a sociedade, isto é, total legitimidade significa apoio total, já zero legitimidade significa total rejeição. O importante, aqui, é observar as mensagens que ficam no meio do espectro da legitimidade, pois são as mensagens consideradas polarizadoras. Nesse sentido, ressonância significa a capacidade de uma mensagem gerar debates em torno de si mesma. Assim, mensagens polarizadoras tem grande ressonância e, consequentemente, visibilidade, a qual é considerada extensão da cobertura da mensagem pelos meios de comunicação em massa.

\section{Análise dos Objetos da Pesquisa}

\section{1. "USA Virus",China}

No dia 11/03/2020, o diretor do Centro de Controle de Prevenção de Doenças dos EUA, Robert Redfield, revelou que alguns nortes-americanos, os quais aparentemente haviam falecido por gripe, foram posteriormente testados positivos para o COVID-19. Em decorrência disso, no dia 12/03/2020, o Ministro de Relações Exteriores da China, Zhao Lijian, afirmou que o Exercito dos Estados Unidos, durante a sétima edição dos Jogos Mundiais Militares do Conselho Internacional do Esporte Militar (2019) em Wuhan, pode ter levado o vírus para a China (REUTERS, 2020), o que caracteriza desinformação do tipo 1. Ao analisar o termo ao qual a fala ficou conhecida no Google Trends, USA virus 1 , consegue-se notar que houve um pico de $100 \%$ no período de 08/03/2020 até 14/03/2020.

\footnotetext{
1 "Vírus dos Estados Unidos", em tradução livre
} 


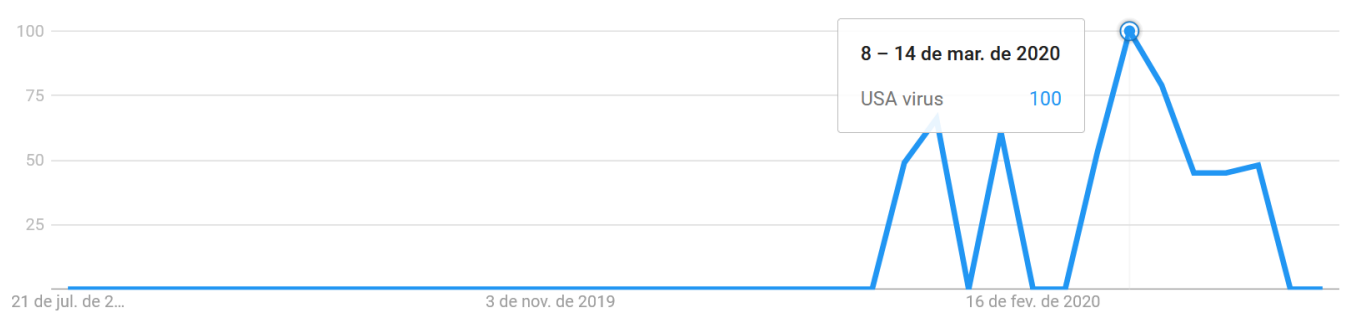

Figura 1. Google Trends: USA virus

\section{2. "Milano non si ferma", Itália}

Em 27/02/2020, o prefeito de Milão Geiseppe Sala compartilhou um vídeo em que era defendido a manutenção das atividades normais em Milão, contendo o slogan "Milano non si ferma" 2, caracterizando a desinformação do tipo 3, por ir contra as orientações da OMS, com a alegação de que o isolamento não é economicamente justificável. Ao analisar o tal slogan, percebe-se um pico de 100 pontos no período de 23/02/2020 até 29/02/2020 no país.

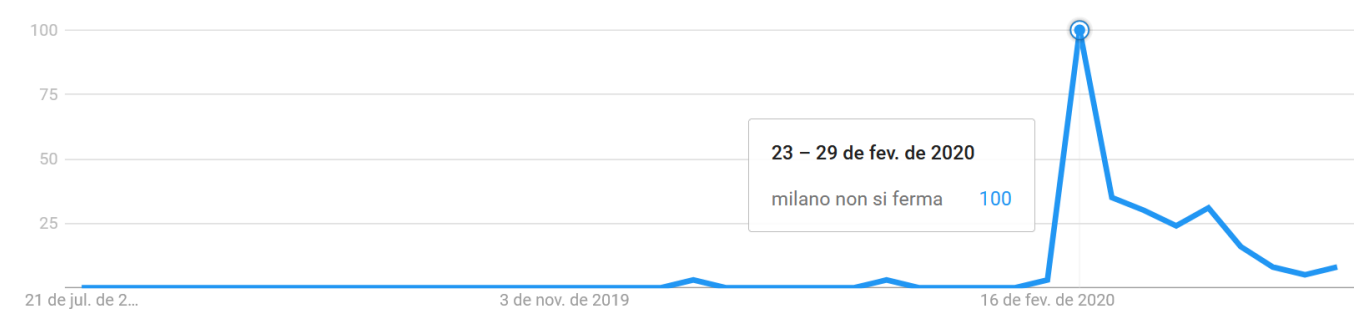

Figura 2. Google Trends: Milano non si ferma

Um mês depois, com a Itália registrando mais de 9 mil mortes pela doença, Sala admitiu que a decisão foi errada (VEJA, 2020). Além disso, durante o período de $20 / 01 / 2020$ até $22 / 03 / 2020$, entre $4,9 \%$ e $7,3 \%$, uma média de $5,87 \%$, de todos as artigos e matérias digitais sobre a COVID-19 na Itália eram falsos (COPPOLA, 2020).

\section{3. "Herd Immunity", Reino Unido}

Nas primeiras semanas, foi adotada a estratégia de "imunidade de grupo", ou "imunidade de rebanho", a qual restringia apenas a circulação de pessoas dos grupos considerados de risco. Tal abordagem era considerada inédita e não tinha respaldo científico sobre sua eficiência, tendo como pilar a necessidade de manutenção das atividades comerciais, caracterizando a desinformação do tipo 3. Diante disso, o Imperial College COVID-19 Response Team fez uma previsão, baseada em simulações computacionais, de um total de cerca de 510 mil mortos se tal estratégia fosse mantida (FERGUSON et al., 2020). Tal estudo, atrelado à internação do próprio primeiro-ministro Boris Johnson (OUL, 2020), fez com que o país abandonasse tal estratégia.

Analisando o termo "Herd Immunity" 3 , percebe-se dois picos de interesse no termo no país: 100 pontos no período 08/03/2020 até 14/03/2020 e 90 pontos no período

\footnotetext{
2"Milão não para", em tradução livre

3 "Imunidade de rebanho", em tradução livre
} 
de 15/03/2020 até 21/03/2020. Além disso, segundo dados da Ofcom, cerca de 50\% dos adultos do Reino Unido foram expostos a pelo menos uma fake news sobre a COVID-19 (MUNCASTER, 2020).

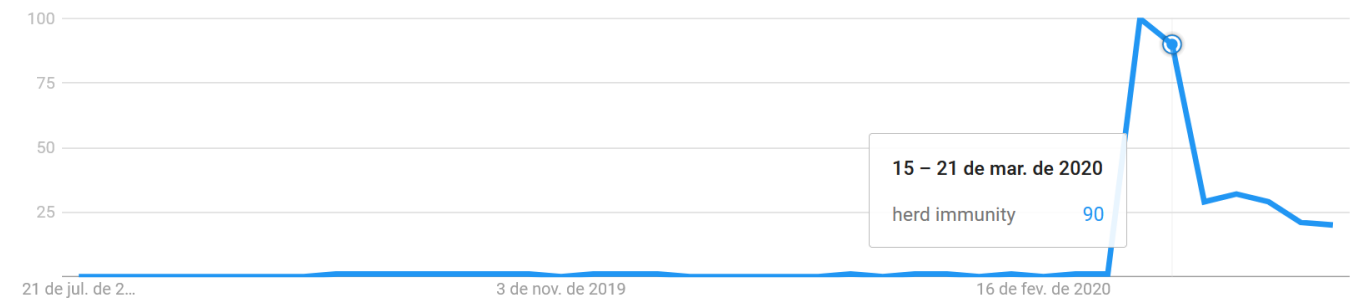

Figura 3. Google Trends: Herd Immunity

\section{4. "Chinese Virus", Estados Unidos}

No dia 16/03/2020, o presidente Donald Trump se pronuncia através de seu Twitter pessoal dizendo: "[...] by the Chinese Virus" 4 (AFP, 2020), caracterizando desinformação do tipo 1. Assim, verifica-se um pico de 100 pontos de interesse pelo termo "Chinese Virus" no período de 15/03/2020 até 21/03/2020.

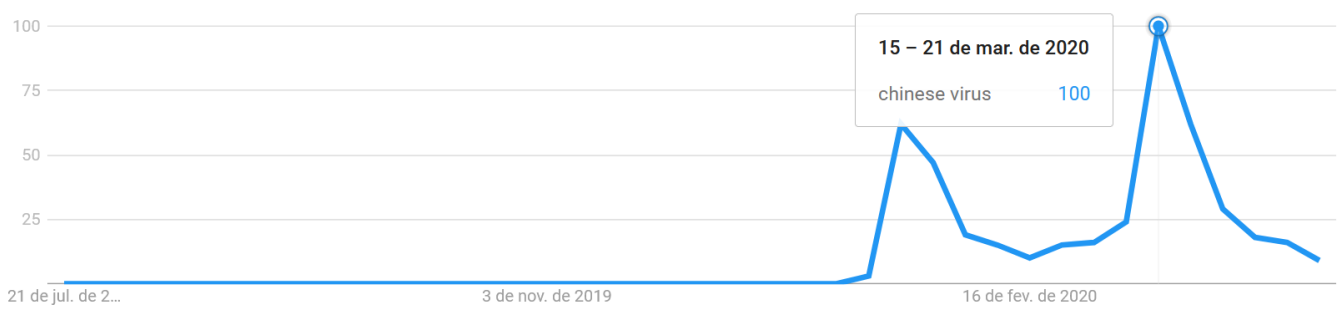

Figura 4. Google Trends: Chinese Virus

\section{5. "Opening Up America Again", Estados Unidos}

No dia 16/04/2020, por meio de uma coletiva de imprensa na Casa Branca, Trump afirmou que "Os Estados Unidos alcançaram uma taxa de mortalidade significativamente menor do que quase todos os outros países. Com base nos dados mais recentes, nossa equipe de especialistas agora concorda que podemos começar a próxima frente de nossa guerra, que estamos chamando de 'Abrindo a América Novamente'. E é isso que estamos fazendo: estamos abrindo nosso país. E nós temos que fazer isso. Os Estados Unidos querem ser abertos, e os americanos querem ser abertos. [...]".

Tal afirmação de Donald Trump foi contradita pela Johns Hopkins University que acompanha os casos de COVID-19 no mundo. A Universidade mostra através dos dados obtidos de 130 países que, até o dia 16/04/2020, 90\% desses países estavam com a taxa de letalidade abaixo dos Estados Unidos, ou seja, 117 nações estão com a taxa inferior em relação aos Estados Unidos (GORE, 2020), configurando desinformação do tipo 2 e 3. Pesquisando o termo "Opening Up America Again", observa-se um pico de 100\% de pesquisas no intervalo de 12/04/2020 a 18/04/2020.

\footnotetext{
4 "Vírus Chinês", em tradução livre
} 


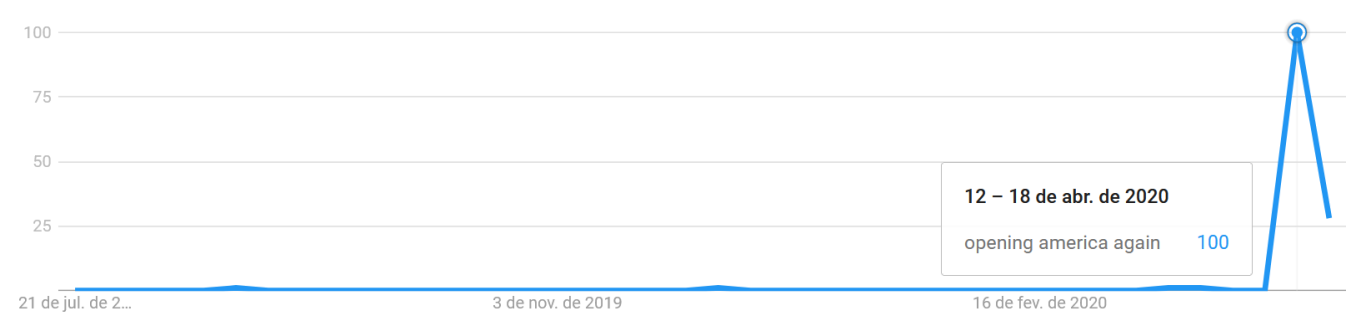

Figura 5. Google Trends: Opening Up America Again

\section{6. "Cloroquina"e "Hidroxicloroquina", Brasil}

Em 21/03/2020, o presidente Jair Bolsonaro faz um tweet promovendo a produção e utilização da hidroxicloroquina. Tal medicação ainda não possui comprovação científica de que seu uso pode ser efetivo contra a COVID-19, caracterizando a fala de Bolsonaro como desinformação do tipo 5. A equipe dos Aos Fatos constatou que, antes da divulgação de Bolsonaro, a taxa de fake news sobre o medicamento no Twitter era cerca de $8 \%$ dos posts mais populares; já após, chegou até 43\% (Libório et al., 2020).

Já no dia 24/03/2020, Bolsonaro fez um pronunciamento em rede nacional, no qual, defendeu o fim do isolamento social, voltou a citar a "suposta eficácia da cloroquina"e comparou a COVID-19 a uma "gripezinha", o que configura desinformações dos tipos 3 e 5. Percebe-se, no Google Trends, no Brasil um pico de $100 \%$ no termo "hidroxicloquina" no período 15/03/2020 até 21/03/2020 e um pico de $70 \%$ no termo "cloroquina" no período de 22/03/2020 até 28/03/2020, correspondendo aos períodos da fala do presidente.

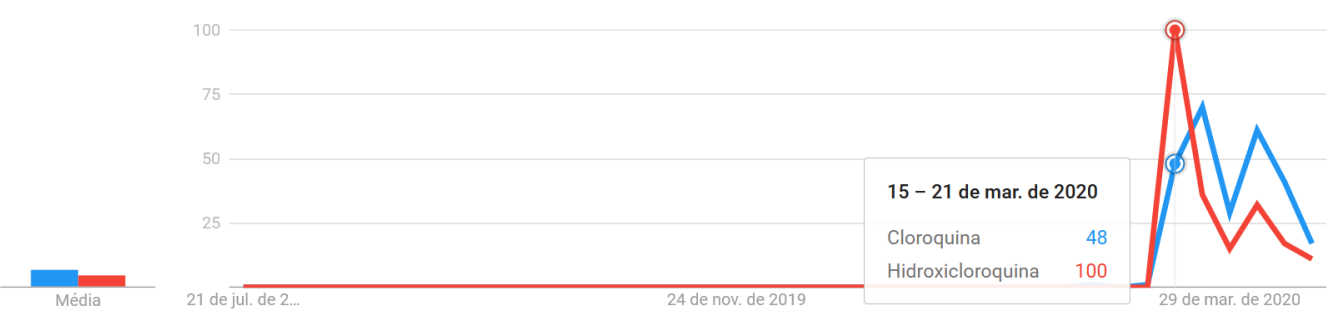

Figura 6. Google Trends: Hidroxicloroquina (vermelho) e Cloroquina (azul)

Tal situação gerou uma crise no governo brasileiro em que o Ministro da Saúde, Luiz Henrique Mandetta, disse que iria contrariar Bolsonaro se as orientações vindas dele não fossem técnicas. Atritos como este levaram à demissão de Mandetta em 16/04/2020, atitude reprovada por uma taxa de $64 \%$ da população (DATAFOLHA, 2020).

\section{Resultado e Discussões}

Ao analisar os casos selecionados, pode-se observar que em, sua grande maioria, havia uma baixa taxa de pesquisa relacionada ao termo analisado e, após a fala de um líder estatal, há um pico muito intenso nas pesquisas. Em todos os termos, com exceção da "cloroquina"no Brasil, o pico em questão é igual ou superior aos $90 \%$ do interesse do público, ou seja, os casos analisados representam os principais momentos de busca no Google dos termos selecionados nos respectivos países. 
Nessa perspectiva, a teoria de Koopmans se mostra presente, pois, em todos os discursos aqui analisados, houve um aumento do interesse sobre os tópicos por parte da população dos países envolvidos, mesmo que o conteúdo de tais falas fosse falso. Isso ocorreu, como já explicado, por conta do aspecto polarizante dos pronunciamentos, o que é potencializado quando se trata de um líder de Estado sendo agente desinformativo.

Portanto, verificando também os estudos apresentados sobre fake news nos países selecionados, é possível inferir que tais falas contribuíram para ampliar a circulação de desinformação nos meios de comunicação, em especial nos veículos de busca online. Além do aspecto desinformativo, tais falas geraram problemas políticos e sanitários, como tensões diplomáticas, no caso dos Estados Unidos e da China, ampliação do número de contaminados, a exemplo da Itália e do Reino Unido, e fragilidade dos órgãos federais, representada no caso brasileiro.

\section{Trabalhos Futuros}

Como trabalhos futuros, destaca-se ampliar a seleção de países analisados, focando nos mais atingidos pela COVID-19, nos quais pode-se aplicar a metodologia adotada. Atrelado a isso, analisar mais detalhadamente as consequências da disseminação de desinformação, tendo como ponto principal a mobilidade urbana nos países, ou seja, como a desinformação sobre a pandemia impactou no isolamento social.

Outra linha para trabalhos futuros, é verificar se a metodologia aplicada aqui pode ser estendida para todos os tipos de desinformação e fake news, não só sobre a pandemia em si. Assim, poderá ser constatada uma ferramenta para medir a propagação dos mais diversos tipos de desinformação.

\section{Referências}

[1] AFP. Trump: "Vírus chinês"é denominação "muito adequada"para coronavírus. [S. 1.], 12 mar. 2020. Disponível em: https://noticias.uol.com.br/ultimasnoticias/afp/2020/03/17/trump-diz-que-virus-chines-e-denominacao-muitoadequada-para-coronavirus.htm. Acesso em: 20 abr. 2020.

[2] BESSI, Alessandro et al. Science vs Conspiracy: Collective Narratives in the Age of Misinformation. Plos One, [s.1.], v. 10, n. 2, p.1-17, 23 fev. 2015. Public Library of Science (PLoS). Disponível em: http://dx.doi.org/10.1371/journal.pone.0118093. Acesso em: 20 abr. 2020.

[3] COPPOLA, Daniela. Share of online fake news related to coronavirus (COVID-19) in Italy between January and March 2020. Statista, [s. 1.], 8 abr. 2020. Disponível em: https://www.statista.com/statistics/1109490/share-of-coronavirus-fake-newsitaly/. Acesso em: 22 abr. 2020.

[4] DATAFOLHA, Equipe. Opinião sobre a pandemia coronavírus. [S. 1.], 17 abr. 2020. Disponível em: http://media.folha.uol.com.br/datafolha/2020/04/18/2d1a9a8c156556fdfead557dc693 990eag.pdf. Acesso em: 23 abr. 2020.

[5] FERGUSON, Neil $M$ et al. Report 9: Impact of non-pharmaceutical interventions (NPIs) to reduce COVID19 mortality and healthcare demand. 
Imperial College, [s. 1.], 16 mar. 2020. DOI 10.25561/77482. Disponível em: https://spiral.imperial.ac.uk:8443/bitstream/10044/1/77482/14/2020-03-16COVID19-Report-9.pdf. Acesso em: 22 abr. 2020.

[6] GORE, D'Angelo; Trump's Inaccurate COVID-19 Death Rate Comparison. FactCheck, [S. 1.], 17 abr. 2020. Disponível em: https://www.factcheck.org/2020/04/trumpsinaccurate-covid-19-death-rate-comparison/. Acesso em: 21 abr. 2020.

[7] HOWELL, Lee. Digital Wildfires in a Hyperconnected World. In: Global Risks 2013: An Initiative of the Risk Response Network. [S. 1.], 4 mar. 2013. Disponível em: http://reports.weforum.org/global-risks-2013/risk-case-1/digital-wildfires-in-ahyperconnected-world/. Acesso em: 30 maio 2020.

[8] KOOPMANS, Ruud. Movements and media: Selection processes and evolutionary dynamics in the public sphere. Theory and Society 33, 367-391 (2004). Disponível em: https://doi.org/10.1023/B:RYSO.0000038603.34963.de. Acesso em: 20 abr. 2020.

[9] LIBÓRIO, Bárbara et al. Como a desinformação sobre cloroquina se multiplicou no Twitter após aval de Bolsonaro à droga. Aos Fatos. Brasil, p. 1-13. 26 mar. 2020. Disponível em: https://aosfatos.org/media/cke_uploads/2020/03/26/radar-0125mar_uJkN0KK.pdf. Acesso em: 21 abr. 2020.

[10] MUNCASTER, Phil. Half of UK Adults Exposed to \#COVID19 Fake News. Info Security, [S. 1.]. 2020. Disponível em: https://www.infosecurity-magazine.com/news/halfof-uk-adults-exposed-to/. Acesso em: 22 abr. 2020.

[11] OUL, Editorial. Boris Johnson é transferido para a UTI após em quadro de COVID-19. [S. 1.], 6 abr. 2020. Disponível em: https://noticias.uol.com.br/internacional/ultimasnoticias/2020/04/06/boris-johnson-e-transferido-para-a-uti-apos-piora-em-quadrode-covid-19.htm. Acesso em: 20 abr. 2020.

[12] POSETTI, Julie; BONTCHEVA, Kalina. Disinfodemic: Deciphering COVID-19 disinformation. [S. 1.], 10 abr. 2020. Disponível em: https://en.unesco.org/sites/default/files/disinfodemic_deciphering_covid19_disinformation.pdf. Acesso em: 30 maio 2020.

[13] REUTERS. Porta-voz da China sugere que militares dos EUA levaram coronavírus para o país. [S. 1.], 12 mar. 2020. Disponível em: https://oglobo.globo.com/mundo/portavoz-da-china-sugere-que-militares-dos-eua-levaram-coronavirus-para-pais24300774, Acesso em: 20 abr. 2020.

[14] ROGERS, Simon. What is Google Trends data — and what does it mean?. [S. 1.], 1 jul. 2016. Disponível em: https://medium.com/google-news-lab/what-is-google-trendsdata-and-what-does-it-mean-b48f07342ee8. Acesso em: 16 jun. 2020.

[15] VEJA, Redação. Prefeito de Milão admite erro após campanha para não parar a cidade. [S. 1.], 27 mar. 2020. Disponível em: https://veja.abril.com.br/mundo/prefeitode-milao-admite-erro-apos-campanha-para-nao-parar-a-cidade/. Acesso em: 20 abr. 2020.

[16] VOSOUGHI, Soroush; ROY, Deb; ARAL, Sinan. The spread of true and false news online. Science, [s.1.], v. 359, n. 6380, p.1146-1151, 8 mar. 2018. American Association for the Advancement of Science (AAAS). Disponível em: http://dx.doi.org/10.1126/science.aap9559. Acesso em: 20 abr. 2020 